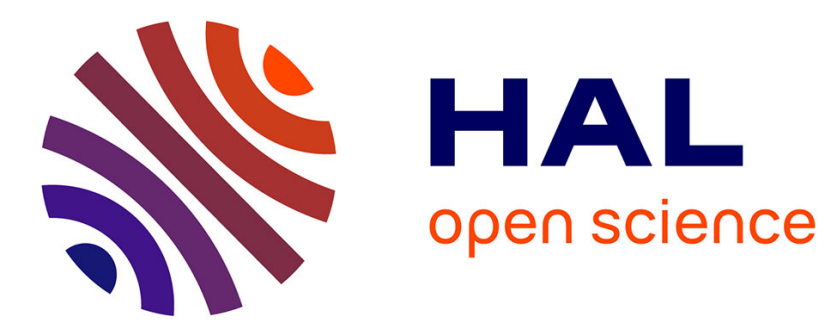

\title{
Hafnium Oxidation at High Temperature in Steam
}

Severine Guilbert, Alice Viretto, Marc Barrachin, Céline Tanguy, Martin

\author{
Steinbrueck, Juri Stuckert
}

\section{To cite this version:}

Severine Guilbert, Alice Viretto, Marc Barrachin, Céline Tanguy, Martin Steinbrueck, et al.. Hafnium Oxidation at High Temperature in Steam. Journal of Nuclear Materials, 2021, 550, pp.1-14. 10.1016/j.jnucmat.2021.152901 . hal-03208869

\section{HAL Id: hal-03208869 \\ https://hal.science/hal-03208869}

Submitted on 26 Apr 2021

HAL is a multi-disciplinary open access archive for the deposit and dissemination of scientific research documents, whether they are published or not. The documents may come from teaching and research institutions in France or abroad, or from public or private research centers.
L'archive ouverte pluridisciplinaire HAL, est destinée au dépôt et à la diffusion de documents scientifiques de niveau recherche, publiés ou non, émanant des établissements d'enseignement et de recherche français ou étrangers, des laboratoires publics ou privés.

\section{(ㅇ)(1) $\$$}

Distributed under a Creative Commons Attribution - NonCommercial - NoDerivatives| 4.0 


\title{
Hafnium Oxidation at High Temperature in Steam
}

\author{
S. Guilbert-Banti*, A.Viretto, M. Barrachin \\ Institut de Radioprotection et de Sâreté Nucléaire PSN-RES, Saint Paul les Durance cedex 13115, France \\ C.Tanguy, M. Steinbrück, J. Stuckert \\ Karlsruher Institut für Technologie IAM-AWP, Hermann-von-Helmholtz-Platz 1, 76344 Eggenstein-Leopoldshafen, Germany
}

\begin{abstract}
To assess the potential impact of using hafnium as absorber material in LWRs in high temperature accidental situations, the oxidation behavior of hafnium was studied up to $1400^{\circ} \mathrm{C}$, i.e. at temperature conditions relevant to severe accidents. Different sample geometries were tested and oxidized in steam/argon mixtures, either in a furnace or in a thermogravimetric analyzer. Metallographic examinations, hydrogen measurements and EPMA oxygen profiles were then performed. For hafnium rods/discs, metallographic examinations showed the presence of a dense and protective oxide film after steam oxidation. No or little hydrogen was detected in the metallic part of the rod/disc specimens. The reaction rate can be described by a parabolic law in the tested temperature range in the mid-to-long term, and the value of the effective activation energy determined from the experimental data in steam is in good agreement with the ones published in the literature. The diffusion coefficient of oxygen in hafnium was estimated at each temperature by fitting the experimental oxygen profile obtained on hafnium rods and its temperature dependence is derived in the temperature range $700-1400^{\circ} \mathrm{C}$. The hafnium claddings produced for the application in integral bundle tests exhibited a lower resistance to steam oxidation than hafnium rods/discs. Metallographic examinations showed a non-protective layer and a significant hydrogen amount was picked up by hafnium claddings. Above $800^{\circ} \mathrm{C}$, the oxidation rate for hafnium claddings follows a cubic to quartic law and the effective activation energy was determined in the temperature range $800-1100^{\circ} \mathrm{C}$. These tests highlighted the influence of the surface conditions on the oxidation rate of hafnium in steam. However, hafnium oxidation rate remains well below the oxidation rate of zirconium alloys in the same temperature range.
\end{abstract}

\section{Introduction}

Zirconium and hafnium have very similar chemical behaviour, making them difficult to separate in ores. Indeed, hafnium is obtained as a by-product of the extraction process to produce hafnium-free nuclear-grade zirconium. However, their application in the nuclear industry are fundamentally different considering the fact that zirconium has an extremely small neutron absorption cross section whereas hafnium absorbs both thermal and epithermal neutrons. As a result, hafnium has been used in the nuclear industry in some control rods or emergency stop rods since the 1970s, in the United States [1], in Russia [2] and in Japan [3] or in research reactors (for instance in CABRI French research reactor).

In France, it is currently planned to introduce uncladded hafnium absorber rods at the periphery of the reactor core in order to reduce the neutron flux received by the vessel. In severe accident conditions, the impact of additional energy released by the interaction between hafnium and steam (energy of the same order of magnitude as that produced by the oxidation of zirconium, $611 \mathrm{~kJ} \mathrm{~mol}^{-1}$ for Hf and $583 \mathrm{~kJ} \mathrm{~mol}^{-1}$ for $\mathrm{Zr}$ at $1500^{\circ} \mathrm{C}$ ) on the progress of core damage has to be assessed. Even if the

\footnotetext{
${ }^{*}$ Corresponding author

Email address: severine.guilbert@irsn.fr (S. Guilbert-Banti)
}

foreseen number of additional hafnium absorber rods is rather limited, the phenomenon to be feared would be the existence of a "runaway temperature" of the reaction between hafnium and steam (as there is for zirconium oxidation) but lower than the runaway oxidation temperature of zirconium $\left(\approx 1500^{\circ} \mathrm{C}\right)$. This runaway would lead to an early acceleration of oxidation phenomena of surrounding materials (and in particular zirconium claddings) with increased hydrogen production and heat release. A further motivation of this work was the application of cladding tubes and shroud made of hafnium in the QUENCH17 bundle test at KIT [4].

For temperatures lower than $500^{\circ} \mathrm{C}$, there are some studies on the corrosion of hafnium in humid atmospheres [5-10]. The study of Rishel [7, 8] which is the most exhaustive of the available works, allowed to characterize three successive oxidation regimes, known as pre-transition (characterized by the formation of an adherent oxide layer), post-transition (characterized by the partial transformation of the oxide layer adhering to nodules) and spalling, characterized by deterioration of the oxide layer. These studies also highlighted the potential effect of material impurities (iron and zirconium) in hafnium on its corrosion resistance $[10,11]$. Iron impurity tends to increase the corrosion resistance while zirconium leads to a corrosion resistance decrease.

For temperatures of interest for severe accident conditions 
(i.e. above $700^{\circ} \mathrm{C}$ ), hafnium oxidation has been poorly investigated. Only D'yachkov's experiments [12] carried out in the 700 to $1200^{\circ} \mathrm{C}$ temperature range at atmospheric pressure provide some data. D'yachkov's results show that hafnium has a better resistance to corrosion under steam than zirconium. In his experimental conditions, the corrosion kinetics obeys in the very beginning of the experiment ( $\leq 0.2 \mathrm{~h}$ between 800 to $1200^{\circ} \mathrm{C}$ ) to the Evans' equation [13] combining parabolic and linear regimes. At intermediate times, the data can be characterized by a parabolic-type behaviour while at larger times $(\geq$ $1 \mathrm{~h}$ ), the corrosion kinetics can be fitted by a cubic-type expression. It must be stressed that contrary to what is observed at lower temperatures, no pure linear oxidation was revealed in the D'yachkov's tests performed at temperatures above $700^{\circ} \mathrm{C}$.

During the first phase of a severe accident, the steam velocities range from 0.95 to $4.8 \mathrm{~m} \mathrm{~s}^{-1}$, i.e. much higher than the one considered in the D'yachkov's study carried out with a gas velocity of $0.06 \mathrm{~m} \mathrm{~s}^{-1}$. Besides, the nature of impurities and the geometry of the tested material were not specified in D'yachkov's work in such a way that it is difficult to consider his results completely transposable to our conditions of interest. Therefore, new tests were undertaken to confirm the oxidationresistance behavior of hafnium under steam atmosphere at high temperature with steam velocities representative of severe accidents and to determine oxidation kinetics up to $1400^{\circ} \mathrm{C}$, temperature conditions relevant to severe accidents.

In this paper, we report two sets of data on hafnium steam oxidation obtained independently by IRSN and KIT up to $1400^{\circ} \mathrm{C}$ on different sample geometries (rod, cladding, and dises) and purities. The present paper is divided in three main parts, the first related to the description of materials and methods, the second and the third ones where the experimental data are presented and discussed, respectively.

\section{Materials and Methods}

\subsection{Materials}

Three different hafnium specimens were tested: rods $(20 \mathrm{~mm}$ long, $6.35 \mathrm{~mm}$ in diameter), discs ( $2 \mathrm{~mm}$ thick, $20 \mathrm{~mm}$ in diameter), and cladding (outer diameter $10.75 \mathrm{~mm}$, thickness $725 \mu \mathrm{m}$, $20 \mathrm{~mm}$ long). Compositions of the different specimens are given in Table 1. Apart from the geometry, the main difference between the different samples is the zirconium content: $2.7 \mathrm{wt} . \%$ for hafnium rods, $0.76 \mathrm{wt} \%$ for hafnium discs and $1.06 \mathrm{wt} . \%$ for hafnium cladding. This could be an important point to consider since at low temperature, the zirconium content was found to decrease the oxidation resistance of hafnium. Nevertheless, Grebennikov [11] showed that the zirconium impact on the steam oxidation of hafnium at $400^{\circ} \mathrm{C}$ was unsignificant up to $30 \% \mathrm{Zr}$ so that no significant effect of zirconium content on hafnium weight gain should be expected in the 0.7 2.7 wt. \% range considered here. Different levels of iron impurities are also noted, with the lower iron content for cladding and the higher content for rods.
Table 1: Chemical composition of the hafnium specimens

\begin{tabular}{|c|c|c|c|}
\hline Element & $\begin{array}{c}\text { Alfa } \\
\text { Aesar } \\
\text { rods } \\
\text { (ppm) }\end{array}$ & $\begin{array}{c}\text { Haines } \\
\text { \&Maassen } \\
\text { discs } \\
\text { (ppm) }\end{array}$ & $\begin{array}{c}\text { American } \\
\text { Elements } \\
\text { cladding } \\
\text { (ppm) }\end{array}$ \\
\hline $\mathrm{Al}$ & $<25$ & 12 & 20 \\
\hline $\mathrm{C}$ & 30 & & 16 \\
\hline $\mathrm{Cd}$ & & $<3$ & 20 \\
\hline $\mathrm{Co}$ & $<5$ & $<3$ & \\
\hline $\mathrm{Cr}$ & $<30$ & $<3$ & 50 \\
\hline $\mathrm{Cu}$ & $<20$ & 18 & \\
\hline $\mathrm{Fe}$ & 170 & 70 & 20 \\
\hline $\mathrm{H}$ & $<3$ & & \\
\hline $\mathrm{Mn}$ & $<20$ & $<3$ & \\
\hline Mo & $<10$ & 61 & \\
\hline $\mathrm{N}$ & 24 & & \\
\hline $\mathrm{Nb}$ & $<50$ & & 27 \\
\hline $\mathrm{Ni}$ & $<25$ & 5 & 10 \\
\hline $\mathrm{O}$ & 260 & & 26 \\
\hline $\mathrm{P}$ & & & 20 \\
\hline $\mathrm{Pb}$ & $<5$ & 5 & \\
\hline $\mathrm{Si}$ & 38 & 94 & 20 \\
\hline $\mathrm{Sn}$ & $<10$ & $<3$ & \\
\hline $\mathrm{Ta}$ & $<1$ & & \\
\hline $\mathrm{Ti}$ & $<20$ & 12 & 50 \\
\hline $\mathrm{U}$ & $<2$ & & \\
\hline $\mathrm{V}$ & $<10$ & $<3$ & \\
\hline W & $<20$ & & \\
\hline $\mathrm{Mg}$ & $<10$ & 10 & \\
\hline $\mathrm{Zr}(\mathrm{wt} \%)$ & 2.72 & 0.76 & 1.06 \\
\hline
\end{tabular}

\subsection{Oxidation conditions}

High temperature isothermal steam oxidation tests were performed in different facilities either in a tube furnace or in a thermogravimetric analyzer.

Regarding the furnace facilities:

- the IRSN apparatus (OHTAVA) is a vertical resistive furnace coupled with a steam generator. Inside the furnace, an alumina tube is open at the lower end in order to allow sample introduction in the hot zone while the steam flow is established, and water-quenching at the end of the oxidation period. The tests were performed at atmospheric pressure. At the end of the test, the sample was quenched by dropping it into a water bath.

- for KIT, a horizontal furnace (BOX) is coupled with a quadrupole mass spectrometer to measure the composition of the off-gas mixture, especially the hydrogen release (Balzers GAM 300). Specimens were heated up in inert atmosphere $(50 \mathrm{NL} / \mathrm{h} \mathrm{Ar})$ to the desired temperature with a heating rate of $20^{\circ} \mathrm{Cmin}^{-1}$ and steam was then injected. The mass gain rate is deduced from hydrogen concentration data recorded by the spectrometer. 
Regarding the thermogravimetric measurements:

- the IRSN thermogravimetric analyzer is a SETARAM SETSYS thermobalance. Isothermal oxidations were conducted at atmospheric pressure. The heat-up rate was $30^{\circ} \mathrm{Cmin}^{-1}$ under flowing argon and the steam was introduced when the test temperature is reached. The specimen was suspended to the high precision balance via an alumina specimen holder. The sample was air-quenched at the end of the test.

- KIT thermogravimetric tests were conducted in a NETZSCH STA 409 analyzer, with a special steam furnace, coupled to a quadrupole mass spectrometer (NETZSCH Aeolos), which is used for process control, mainly to check the purity and composition of the gas mixture. The construction of the furnace enables to work under pure steam atmosphere, although $3 \mathrm{NL} / \mathrm{h}$ argon were injected as protective gas. The sample was heated up in inert atmosphere $(3 \mathrm{NL} / \mathrm{h} \mathrm{Ar})$ to the desired temperature with a heating rate of $10^{\circ} \mathrm{C} \mathrm{min}^{-1}$ and steam was then introduced.

All the experimental conditions are summarized in Table 2. Isothermal tests were conducted at temperature ranging from 700 to $1400^{\circ} \mathrm{C}$ and for durations up to $63 \mathrm{~h}$ (depending on the temperature). Regarding hafnium cladding, open samples were used, leading thus to two-side oxidations. It must be stressed that in the temperature ranges in which the experiments were performed $\alpha$-Hf and $\mathrm{HfO}_{2}$ do not undergo polymorphic changes [14].

\subsection{Sample characterization}

The samples were characterized by different means:

- Weight and length of the specimens were measured with an accurancy of $\pm 0.2 \mathrm{mg}$ and $\pm 0.1 \mathrm{~mm}$, respectively, at the $95 \%$ confidence level, before and after the test. The weight divided by the oxidation surface $S$, i.e. the initial specimen surface exposed to steam, $(\Lambda m / S)$, is defined as the weight gain thereafter. For thermobalance measurements, the mass change was recorded continuously. After oxidation, specimens were cut using a diamond saw for analyses. Rings or slices were kept for the hydrogen analysis and cross sections were embedded in an epoxy resin and polished for metallographic examinations.

- The average hydrogen content of the samples was measured before and after steam oxidation by gas fusion method using an ON/H-mat 286 JUWE analyzer (thermal conductivity cell). Several measurements were systematically performed in order to have a good assessment of the scattering of the hydrogen contents. Calibration of the analyzer is checked regularly by analyzing a hydrogen certified reference standard $(17.7 \pm 2.1 \mathrm{wtppm})$. The hydrogen content uncertainty was calculated as the quadratic sum of the hydrogen standard uncertainty and the standard deviation of the sample measurements. For some other tests, the hydrogen content was also measured by hot extraction using a quadrupole mass spectrometer (Balzers GAM 300).
- The outer oxide thickness for each sample was measured at twelve different locations and the mean thickness value was calculated as the average of these different measurements. The oxide thickness uncertainty was calculated as the standard deviation of the sample measurements multiplied by 2 (the uncertainty of the measurement instrument being negligible in comparison to the standard deviation of the mean measured thickness).

- Scanning Electronic Microscopy (SEM) images were obtained with a field-emission SEM (Zeiss SIGMA VP500) equipped with a backscattered electron detector.

- Radial oxygen concentration profiles were obtained by Electron Probe MicroAnalysis (EPMA, CAMECA SX100 electron microprobe). The oxygen $K \alpha$ line was measured with a W/Si multi-layer synthetic crystal. Profiles were performed with a $1 \mu \mathrm{m}$ or $2 \mu \mathrm{m}$ stage displacement step depending on the profile length.

\section{Experimental Results}

\subsection{Oxidation kinetics}

The measured weight gains, $\Delta m / S$, obtained under the different conditions (sample and facility) are plotted versus steam oxidation duration in the 800 to $1400^{\circ} \mathrm{C}$ temperature range for rods and discs in Figure 1, and for claddings in the 800 to $1200^{\circ} \mathrm{C}$ temperature range in Figure 2.

For rods and dises, the TGA curves show initially fast increase and then the weight gain increases more and more slowly with time. A good agreement is observed for measurements performed with the NETZSCH and the SETARAM analyzers, except at $1200^{\circ} \mathrm{C}$ initial phase. The TGA data are consistent with tests performed in the furnaces. These results are slightly higher than D'yachkov's data (weight gains after 3 h reported in Figure 1) obtained by a gravimetric method in the 800 to $1200^{\circ} \mathrm{C}$ temperature range. The observed difference between both sets of data is likely not due to the steam velocity since the values used in this study covers the steam velocity considered in [12]. Consequently there is apparenlty no influence of the steam velocity under the conditions tested. If the purity of D'yachkov's specimens $(99.70 \%)$ is comparable to that of our samples, the nature and amounts of the Hf impurities (unknown in the D'yachkov's study [12]) could be a part of the explanation about this difference.

The comparison of the oxidation rate between hafnium rods and hafnium claddings (Figure 2) shows that the latters present oxidation rates up to 4 times higher than hafnium rods, especially at the lowest temperatures.

\subsection{Metallographic examinations}

After steam oxidation, the rod sample surface color has turned to a greyish-black color, which is characteristic of a rather substoechiometric hafnium oxide (stoechiometric hafnia is off-white) (Figure 3). A white color is observed at the cracks. BSE images show the presence of a dense and adherent oxide 
Table 2: Experimental conditions of the oxidation tests

\begin{tabular}{ccccc}
\hline Parameter & \multicolumn{2}{c}{ TGA } & \multicolumn{2}{c}{ Furnace } \\
& SETARAM & NETZSCH & OHTAVA & BOX \\
\hline \hline Steam flow rate $\left(\mathrm{g} \mathrm{h}^{-1}\right)$ & 29 & 6 & $100-500$ & 50 \\
\hline Argon flow rate $(\mathrm{NL} / \mathrm{h})$ & 120 & 0.05 & $120-600$ & 50 \\
\hline Steam/argon ratio & $50-50$ & $95-5$ & $50-50$ & $55-45$ \\
\hline Test temperature $\left({ }^{\circ} \mathrm{C}\right)$ & $1000-1400$ & $800-1200$ & $700-1200$ & $1200-1400$ \\
\hline Steam velocity $\left(\mathrm{m} \mathrm{s}^{-1}\right)$ & $0.52-0.75$ & $0.015-0.02$ & $0.42-2.51$ & $0.17-0.26$ \\
\hline
\end{tabular}
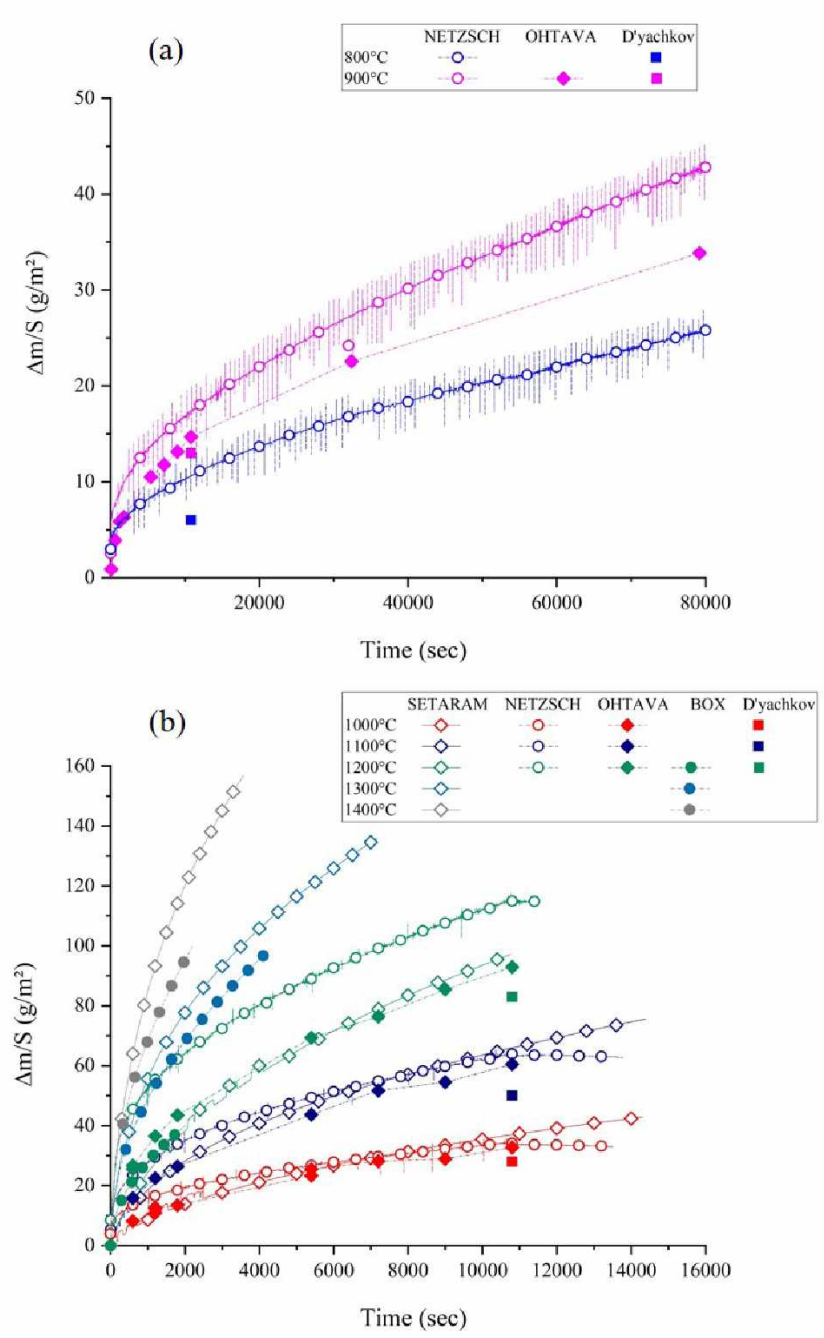

Figure 1: Weight gain versus time for hafnium rods and discs in the temperature range (a) 800 to $900^{\circ} \mathrm{C}$ and (b) 1000 to $1400^{\circ} \mathrm{C}$, comparison between TGA and furnace results (BOX: discs, SETARAM: rods, OHTAVA: rods, NETZSCH: discs), comparison with the D'yachkov's data [12]

film on the rod sample (Figure 4). Oxide grains are columnar and elongated in the growth direction. The oxide/metal interface is rather smooth for all tested conditions. For a given oxidation duration, the oxide thickness increases with the temperature (Figure 5).

On the cladding sample, a porous and white oxide has formed

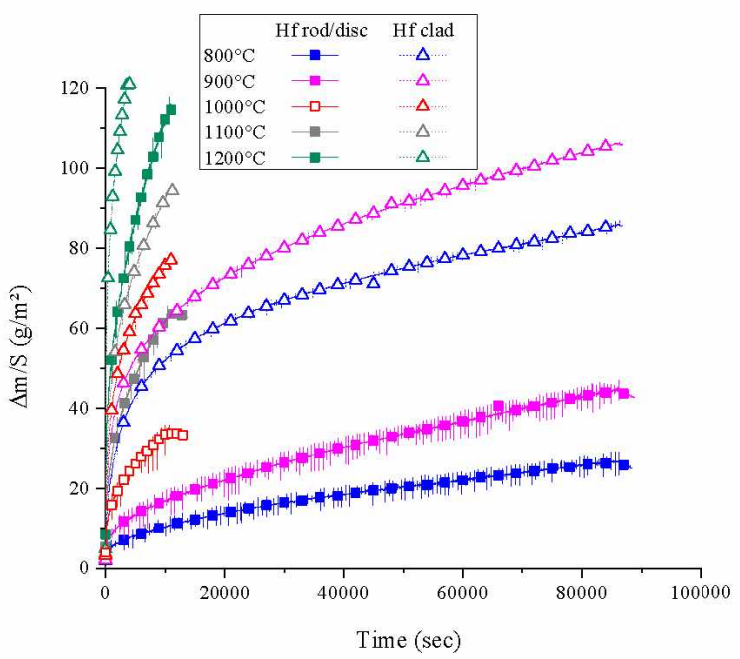

Figure 2: Weight gain versus time for hafnium rod/disc in the 800 to $1200{ }^{\circ} \mathrm{C}$ temperature range, comparison with hafnium cladding results, TGA measurements

(Figure 3). BSE image confirms the porous character of the oxide layer after long-term oxidation (Figure 6). At the oxide/metal interface, columnar grains can be observed.
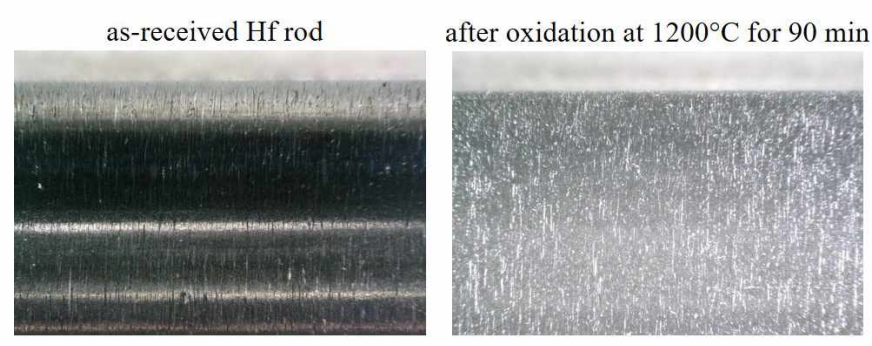

as-received Hf cladding

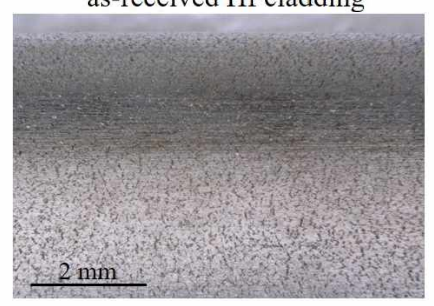

after oxidation at $900^{\circ} \mathrm{C}$ for $22 \mathrm{~h}$

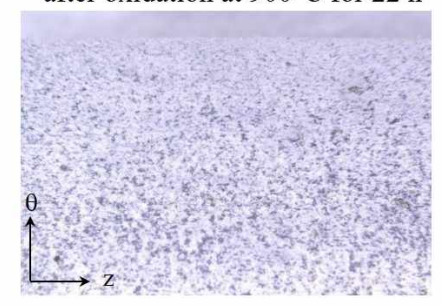

Figure 3: Optical images of hafnium samples before and after steam oxidation 

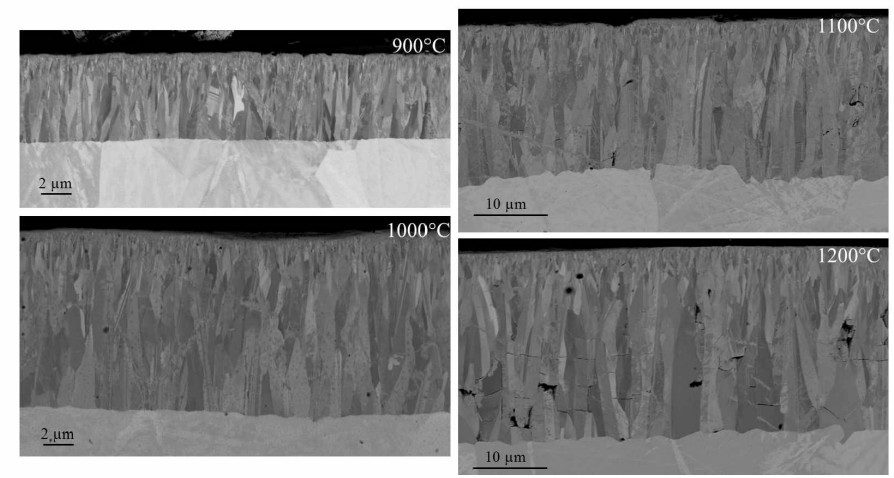

Figure 4: BSE images of hafnium rods after steam oxidation for $3 \mathrm{~h}$ in the 900 to $1200^{\circ} \mathrm{C}$ temperature range

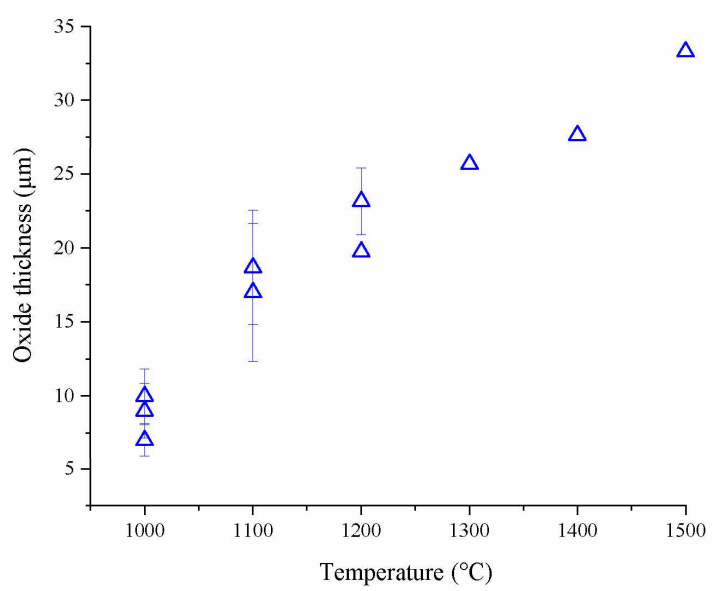

Figure 5: Oxide thicknesses measured on discs or rods after steam oxidation for $3 \mathrm{~h}$ in the 700 to $1200^{\circ} \mathrm{C}$ temperature range

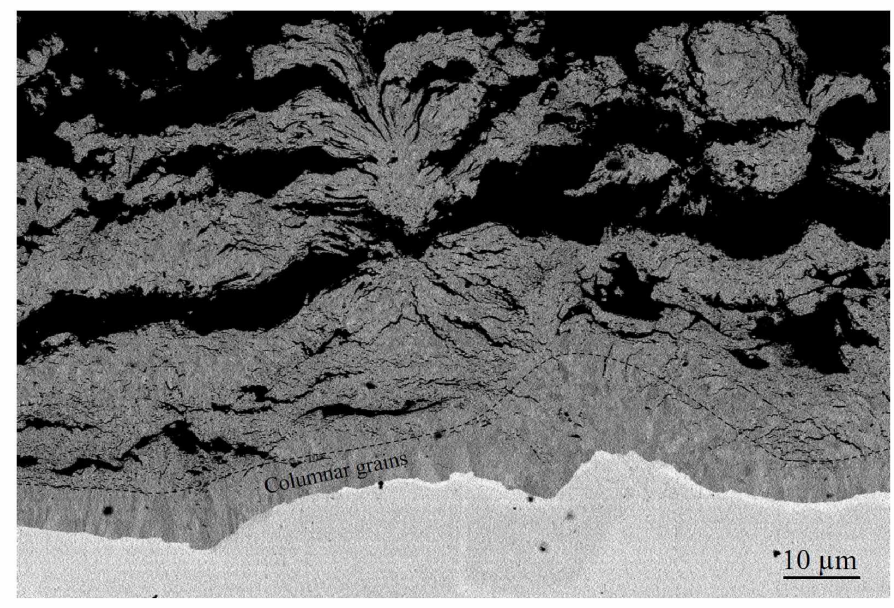

Figure 6: BSE images of hafnium cladding after steam oxidation at $900{ }^{\circ} \mathrm{C}$ after $22 \mathrm{~h}$

\subsection{Hydrogen analyses}

The hydrogen content after oxidation of the hafnium specimens was determined by hot extraction, either using thermal conductivity cell or a quadrupole mass spectrometer. Quadrupole mass spectrometric measurements show a twostage hydrogen release while the temperature is rising, with a shoulder around 500 to $600{ }^{\circ} \mathrm{C}$ and a main peak at around $1400{ }^{\circ} \mathrm{C}$ (Figure 7). Similar results were obtained on Zircaloy and interpreted according to the multiphasic nature of the sample, the hydrogen release at the lower temperature being attributed to hydrogen from the oxide layer and at the higher temperature to hydrogen in the metallic part of the specimen [15].

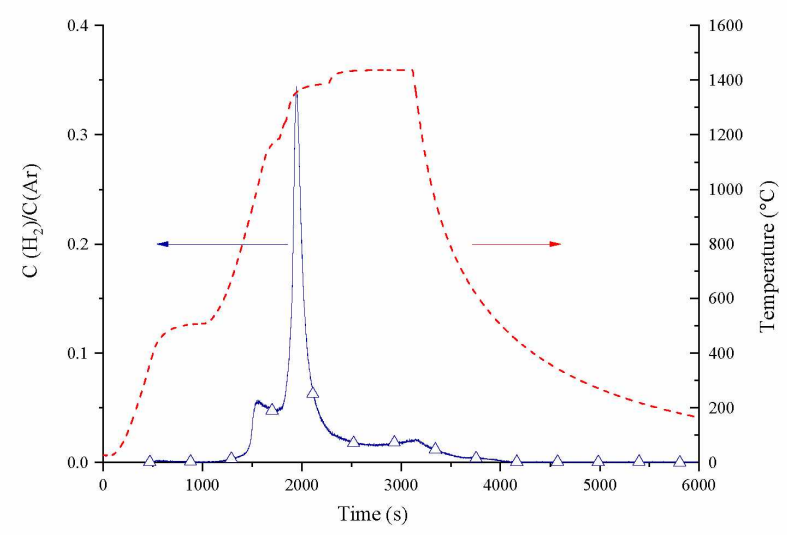

Figure 7: Hydrogen release measured by mass spectrometry during hot extraction for hafnium disc oxidized at $1000^{\circ} \mathrm{C}$ for $3 \mathrm{~h}$

By integrating the area under the peak, it is possible to estimate the amount of hydrogen absorbed by the specimens during the duration of the experiment. For rods and discs, the hydrogen picked up during the experiments was limited, not higher than 2.5 at.\% (140 wtppm). Considering this low value of hydrogen pick-up and the fact that the oxide scale formed was very compact and protective, this indicates that under the conditions tested, Hf rod and disc specimens did not likely undergo breakaway oxidation, for which the metal part is known to act as a pump for hydrogen produced during oxidation [16]. Regarding the Hf-H phase diagram [17], such a low value should not lead to any hydride formation. For cladding, a much larger hydrogen content of 11 at.\% (630 wtppm) was measured at $900^{\circ} \mathrm{C}$ after $22 \mathrm{~h}$.

\subsection{Behavior of Hf cladding under transient and quench con- ditions in the integral bundle test QUENCH-17}

Hafnium tubes were chosen as heater claddings for the QUENCH-17 bundle test devoted to investigation of debris formation during hypothetical severe accident $[4,18]$ because of their higher temperature resistance, $400{ }^{\circ} \mathrm{C}$ higher melting temperature and the about one order of magnitude lower oxidation rate compared to zirconium.

The well instrumented test bundle with a length of about 2 $\mathrm{m}$ (Figure 8) consisted of the shroud tube made of hafnium, 


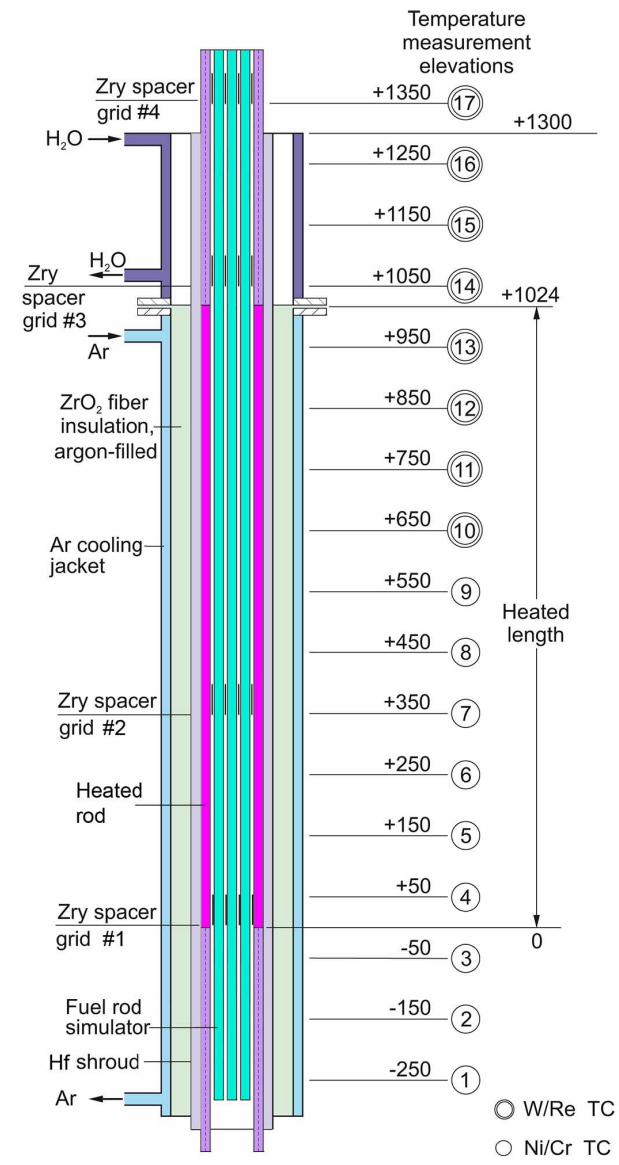

Figure 8: Longitudinal section of the bundle

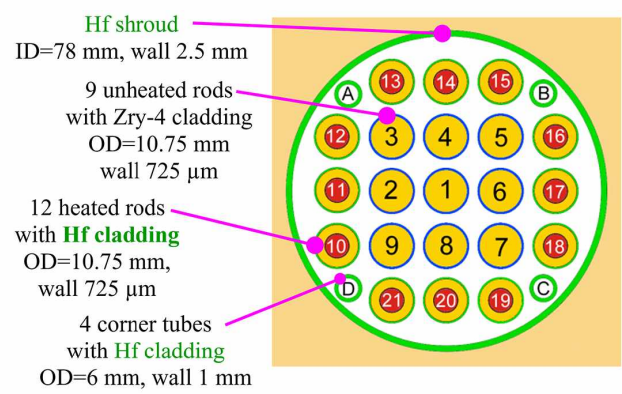

Figure 9: Cross-section of the test bundle, top view

twelve heated peripheral rods (all with hafnium cladding), four hafnium corner rods and nine unheated internal rods with Zry-4 claddings (Figure 9). All Hf parts were produced by American Elements and have the chemical composition presented in Table 1.

The bundle was oxidized in an atmosphere of flowing argon $\left(2 \mathrm{~g} \mathrm{~s}^{-1}\right)$ and superheated steam $\left(2 \mathrm{~g} \mathrm{~s}^{-1}\right.$ or $\left.0.83 \mathrm{~m} \mathrm{~s}^{-1}\right)$ according to the test scenario shown in Figure 10. The experiment lasted over 22 hours and was terminated with reflood by water from the bottom of the bundle with a flow rate of $10 \mathrm{~g} \mathrm{~s}^{-1}$ $\left(0.33 \mathrm{~cm} \mathrm{~s}^{-1}\right.$ for water of $4.15 \mathrm{~m} \mathrm{~s}^{-1}$ for steam produced by water evaporation). Whereas Zry-4 claddings were completely oxidized at the bundle elevations above $600 \mathrm{~mm}$ and collapsed after mechanical impact before reflood, the Hf claddings were completely oxidized only at the hottest elevation of $950 \mathrm{~mm}$ and survived until the end of experiment.

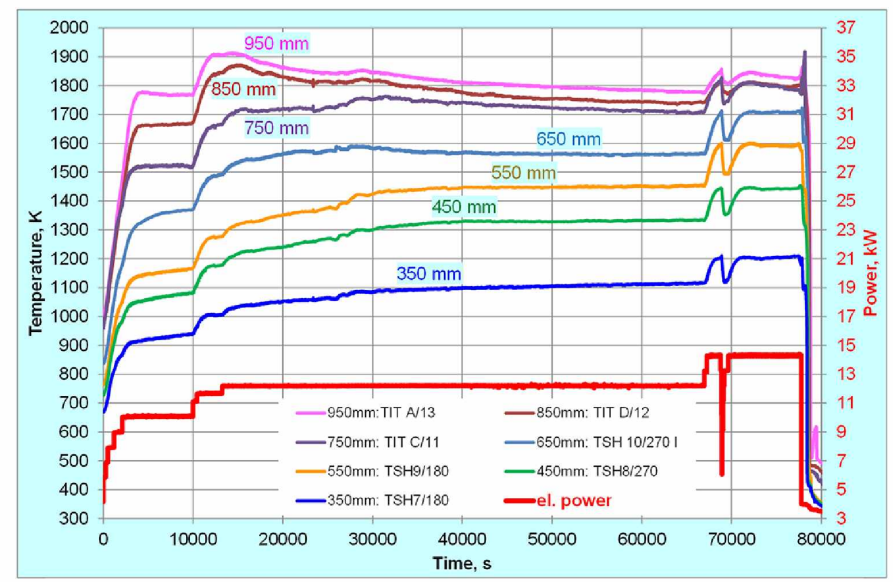

Figure 10: Test conduct: electrical power profile and thermocouple readings at different bundle elevations

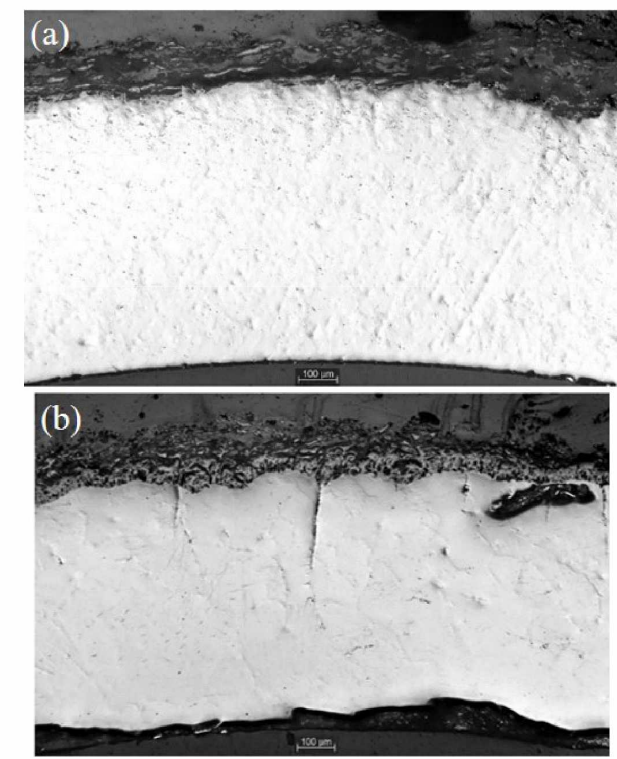

Figure 11: Breakaway oxidation of Hf cladding at bundle elevations (a) $150 \mathrm{~mm}$ with continuous peak cladding temperature $\mathrm{T}=950 \mathrm{~K}$ and (b) $550 \mathrm{~mm}$ with continuous peak cladding temperature $\mathrm{T}=1450 \mathrm{~K}$

Optical microscopy revealed pronounced spalling of oxide layers (breakaway effect) at all elevations with continuous peak cladding temperatures below $1277^{\circ} \mathrm{C}$ (Figure 11). The thickness of the residual oxide was less than $160 \mu \mathrm{m}$, and the relatively ductile low-oxygen part of the $\alpha-\mathrm{Hf}(\mathrm{O})$ layer remained quite thick. The lower picture in Figure 11 indicates that the inner surface of claddings at elevation of $550 \mathrm{~mm}$ has also undergone breakaway oxidation. This was due to the penetration of steam through the through-going cracks formed in the claddings 

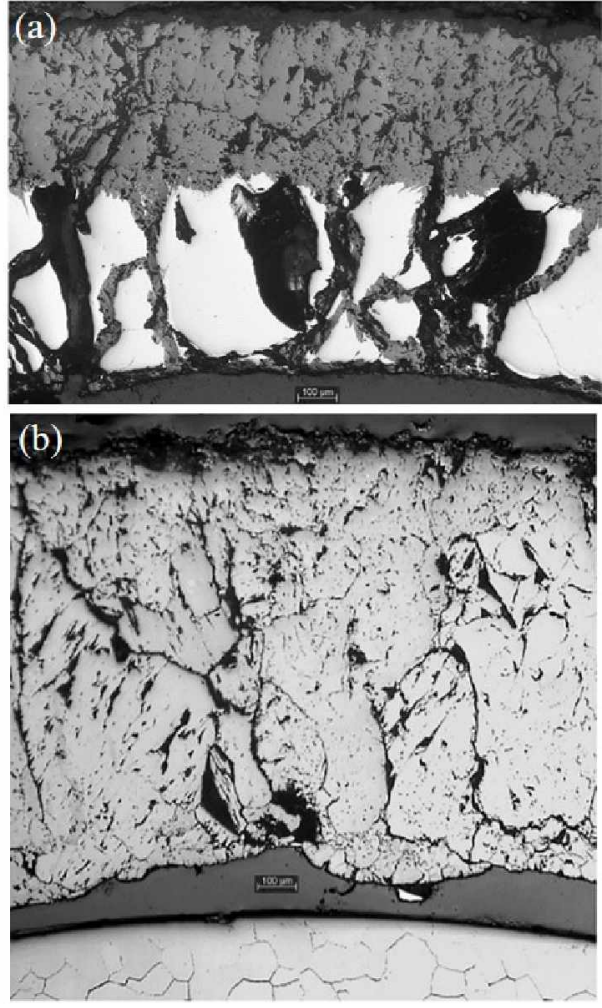

Figure 12: Formation of dense $\mathrm{HfO}_{2}$ layer at the hottest bundle elevations (a) with brittle $\alpha$-Hf(O) layer with through-going oxidized cracks at bundle elevations of $850 \mathrm{~mm}$ with continuous temperature above $1700 \mathrm{~K}$ (b) $\mathrm{ZrO}_{2}$ pellet (low) and completely oxidized Hf cladding at elevation of $950 \mathrm{~mm}$ with continuous temperature above $1800 \mathrm{~K}$

at the upper elevations. The upper picture in Figure 12 shows formation of such cracks in the brittle highly oxygenated $\alpha$ $\mathrm{Hf}(\mathrm{O})$ layer. The oxide layer at this elevation, although rather thick, is dense and mechanically stable. The cladding did not lose its mechanical stability even with complete oxidation at the elevation of $950 \mathrm{~mm}$ (lower picture in Figure 12). In general, long-term high temperature oxidation showed the mechanical stability of the cladding tubes in the test bundle. During quenching, following the long oxidation, no fragmentation of the oxidized Hf claddings was observed. Their residual strength and ductility were sufficient to prevent this.

\section{Discussion}

All the tests performed for this study on hafnium oxidation in steam confirm that this material is much more resistant against oxidation than Zry-4 for the same conditions. For Hf cladding which exhibits in our study the lowest resistance to steam oxidation, Figure 13 shows that the Hf kinetics is strongly reduced in comparison to the Cathcart-Pawel correlation [19] obtained on Zircaloy-4 tubes in flowing steam.

In general, at any given temperature $T$, the kinetics of oxidation can be described by an empirical equation or successive

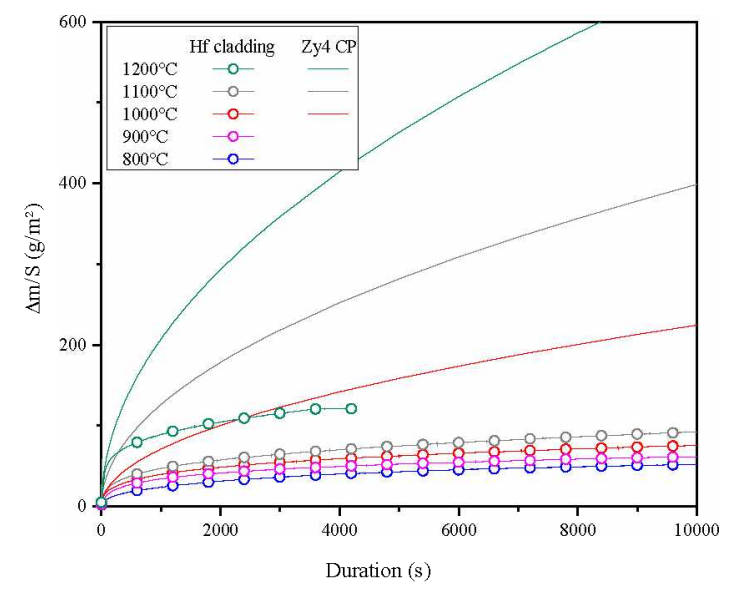

Figure 13: Weight gain of hafnium and Zircaloy-4 versus time for steam oxidation in the temperature range 800 to $1200^{\circ} \mathrm{C}$. For Zircaloy-4, the weight gain is calculated using Cathcart-Pawel (CP) correlation [19]

empirical equations which take the following form:

$$
\left[\frac{\Delta m}{S}\right]=K_{n}(T) t^{1 / n}
$$

with:

- $\Delta m / S$, the weight gain per surface area $\left(\mathrm{g} \mathrm{m}^{-2}\right)$,

- $S$, the initial surface exposed to steam $\left(\mathrm{m}^{2}\right)$

- $K_{n}(T)$, the rate constant for mass gain at $T\left(\mathrm{~g} / \mathrm{m}^{2} / \mathrm{s}^{1 / \mathrm{n}}\right)$,

- $t$, time (s),

- $n$, the order of the kinetics (=1 for linear, $=2$ for parabolic, $=3$ for cubic, $=4$ for quartic).

Figure 14 shows that the experimental data obtained on rods at 1100,1200 and $1400^{\circ} \mathrm{C}$ cannot be represented by a single linear slope in a Ln(weight gain)-Ln(time) axis system all over the duration of the experiment. The "so-called' mid-to-long term kinetics ( $\geq 1000 \mathrm{~s}$, approximately) can be described by a parabolic law whereas the short-term experimental data deviates from this regime, with an almost linear kinetics in the very short times. It is in partial agreement with the observations of D'yachkov who described the oxidation process as a succession of three periods, the first period at the very beginning of the experiment (less than $1000 \mathrm{~s}$ at $1200^{\circ} \mathrm{C}$ ) where the oxidation kinetics follows the Evans' equation [13], the second period (1000 to $3600 \mathrm{~s}$ ) where the data can be described by a parabolic kinetics, the third period after one hour, where his data is fitted by a cubic-type kinetics. In our experiments with rods, the cubic regime is not observable. We will put in evidence in the following section that the parabolic oxidation behavior, at all temperatures, likely obeys the Wagner theory of oxidation, which for hafnium oxidation occurs with the inward 


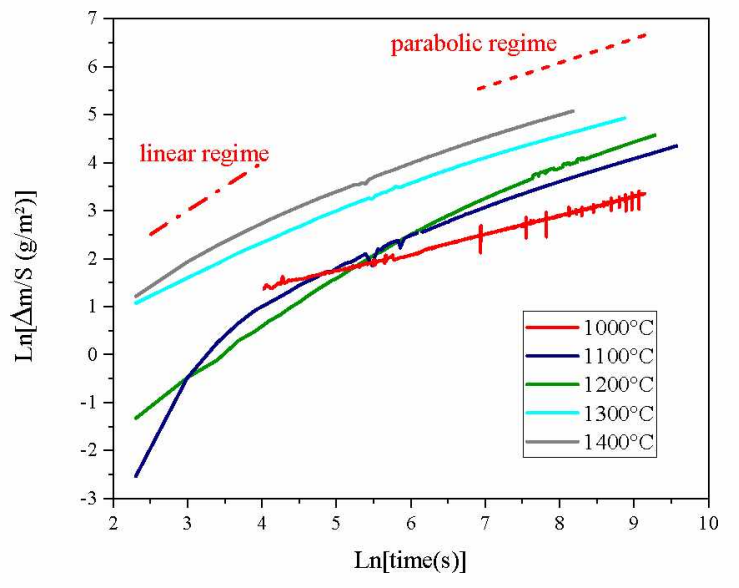

Figure 14: Weight gain of hafnium rods versus time for steam oxidation in the 1000 to $1400^{\circ} \mathrm{C}$ temperature range with for comparison, slopes (red dashed line) corresponding to linear and parabolic kinetics

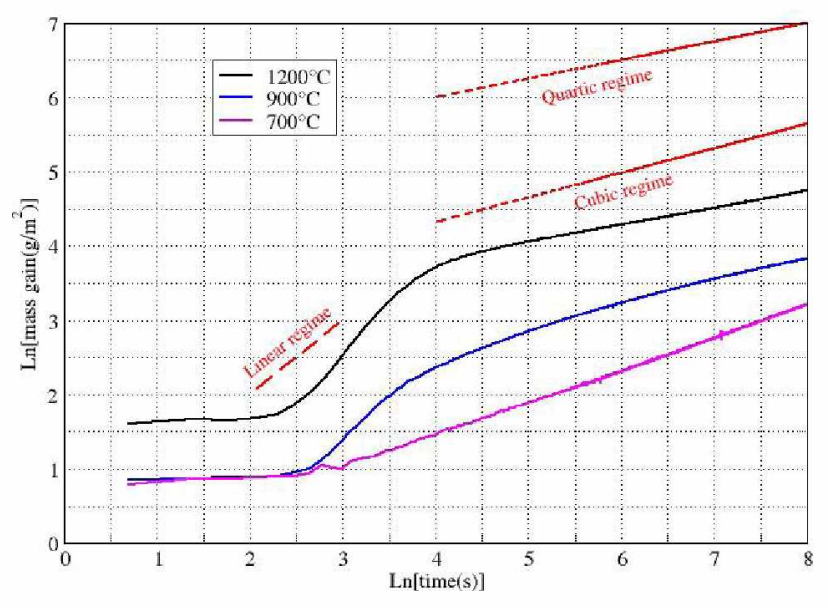

Figure 15: Weight gain of hafnium cladding versus time for steam oxidation at $700^{\circ} \mathrm{C}, 900^{\circ} \mathrm{C}$, and $1200^{\circ} \mathrm{C}$ with for comparison, slopes (red dashed line) corresponding to linear, cubic and quartic kinetics

diffusion of oxygen as ions, via anion vacancies, to react with hafnium at the metal/oxide interface. As we will see therafter, the linear rate relationship, which seems to operate in the initial times of the experiment, may reflect a rate-determining phase boundary process, e.g., transport of oxidizing species in the gas phase.

The behaviour of claddings differs from rods and discs (Figure 15). The experimental data related to cladding put in evidence a lower corrosion resistance with much higher mass gain (e.g. two to three times higher, at $900^{\circ} \mathrm{C}$ after $20 \mathrm{~h}$ ). This result indicates that the oxide is less protective than the oxide grown on discs or rods. This is confirmed by the BSE image showing a porous oxide layer (Figure 6). For cladding, the mid-to-long term kinetics ( $\geq 1000 \mathrm{~s}$, approximately) can be described by a cubic or quartic law in the temperature interval, 900 to $1200^{\circ} \mathrm{C}$ (e.g. $n \approx 3.9$ at $1100^{\circ} \mathrm{C}$ or $n \approx 4.2$ at $1200^{\circ} \mathrm{C}$ ) whereas the short-term experimental data strongly deviate from this regime, with a linear kinetics in the very short times. The oxidation rate decrease for the mid-to-long term kinetics is likely linked to the formation of columnar grains at the metal/oxide interface (see Figure 6). Below $900^{\circ} \mathrm{C}$, the initial linear regime is no more observable whereas the data can be processed over all the duration of the experiment using a cubic-quartic equation.

The difference in terms of overall corrosion resistance can be mainly attributed to the initial linear regime since the order of the mid-to-long term kinetics is higher for cladding $(n=3,4)$ than for rods ( $n=2$ ), meaning that theoretically, at very long times (not investigated in this study), the corrosion rate for rods should converge towards the corrosion rate for cladding. By examining Figures 15 and 14, it can be observed that the transition from the initial linear regime towards the long-term one takes more time for cladding than for rods. The consequence is a much higher initial corrosion for cladding. It may be related to as-received sample characteristics, as residual stresses related to cladding manufacturing, and surface treatment. Also the claddings were manufactured by cold drawing and annealing at $1200^{\circ} \mathrm{C}$ to lower the brittleness of the material, the purity of the atmosphere during this annealing process was not known. A microhardness measurement performed on a crosssection of the as-received tube indicated the presence of dissolved oxygen in the metal. Examination of the sample surface before high temperature oxidation shows a more important surface roughness on hafnium cladding compared to hafnium rods (Figure 3). Also the respective purities of the different tested samples, in particular the iron content lower in Hf cladding material than in the other materials could have played a role. In previous studies related to Hf oxidation in steam atmosphere at lower temperatures (about $500^{\circ} \mathrm{C}$ ) $[3,10]$, it was shown that lower iron contents tends to decrease the oxidation resistance. More quantitatively, a factor between 3 and 4 between corrosions after 24 hours at $500^{\circ} \mathrm{C}$ in steam for samples containing around $20 \mathrm{ppm}$ and $170 \mathrm{ppm}$ of iron (corresponding to the purities of cladding and rods in this study) was determined by Shirayanagi et al. [3], i.e. in agreement with our data at longer times at 800 to $1000^{\circ} \mathrm{C}$ (Figure 1). As previously mentioned, another difference between cladding and rod occurs after 1000 $s$ where the cubic/quartic kinetics is more appropriate than the parabolic one to represent the cladding data. Such deviation from the parabolic law was already observed for Zircaloy below $900^{\circ} \mathrm{C}$ for long corrosion times while a parabolic rate law is usual observed above $1000^{\circ} \mathrm{C}$ [20-22]. For Zircaloy, it is suggested [23] that the change in oxidation kinetics is linked to the zirconia phase transformation from tetragonal to monoclinic structures in the $\mathrm{Zr}-\mathrm{O}$ binary phase diagram ${ }^{1}$. Such

\footnotetext{
${ }^{1}$ There is no agreeement in the international community about this explanation. Other authors stipulate that the tetragonal phase is stabilized to lower temperatures by compressive stress.
} 
explanation is doubtful in our case since all our experiments were performed much below the monoclinic-tetragonal transition temperature, $1670^{\circ} \mathrm{C}$. A combination of oxygen diffusion via crystallite boundaries and an increasing crystallite size with oxide thickness previously suggested for zirconium alloys [24] could explain departures from parabolic oxidation kinetics in the direction of cubic (or quartic) rate laws for hafnium. Further microscopic examinations would be necessary to confirm this interpretation.

\subsection{Rods and discs}

\subsubsection{Parabolic regime characterization}

In Figure 16, we have performed a linear regression of our data related to rods for times higher than $1000 \mathrm{~s}$ in a $\mathrm{Ln}$ (weight gain)-Ln(time) plot. It is then possible to establish that, after the initial oxidation regime lasting about $1000 \mathrm{~s}$, the oxidation kinetics of hafnium in steam in the temperature range between 1000 and $1400^{\circ} \mathrm{C}$ follows a parabolic law with $n$ between 1.8 and 2.2. It must be underscored that these values of $n$ obtained in this work are slightly lower than those determined respectively by D'yachkov [12] under steam (between 2.0 and 2.3 below $1 \mathrm{~h}$ and significantly higher after $1 \mathrm{~h}$, between 2.6 and 3.4 in the cubic regime) and Smeltzer [25] under oxygen at $1200^{\circ} \mathrm{C}$ $(n=2.3)$. At this stage there is no explanation about this difference.

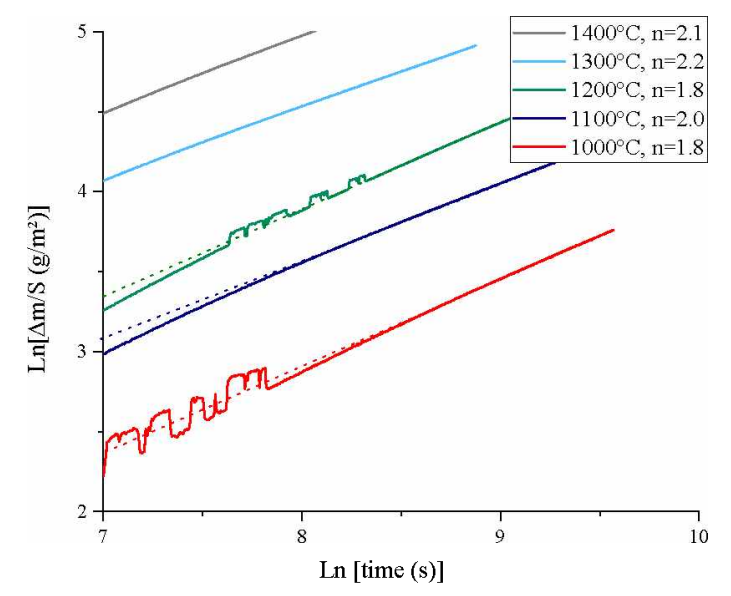

Figure 16: Weight gain of hafnium rods versus time for steam oxidation in the $1000-1400^{\circ} \mathrm{C}$ temperature range

The rate constants, $K_{n}$ with $\mathrm{n}=2$, are evaluated from the slopes of linear section of each curve presented in Figure 16. They are compared to the rate constants obtained by D' yachkov under steam [12] and by Smeltzer under oxygen [25] in Figure 17. Results in flowing steam are in good agreement with Smeltzer results obtained in oxygen and also with the results obtained by D'yachkov in steam. The good agreement between the rate constants for oxygen and for steam suggests that the limiting mechanism for steam oxidation is of the same nature as for oxygen, that is, oxygen diffusion through the oxide layer.
It is likely that the diffusion mechanism of oxygen in hafnia is similar to the one in zirconia, with oxygen diffusing to the metal/oxide interface through anionic vacancies.

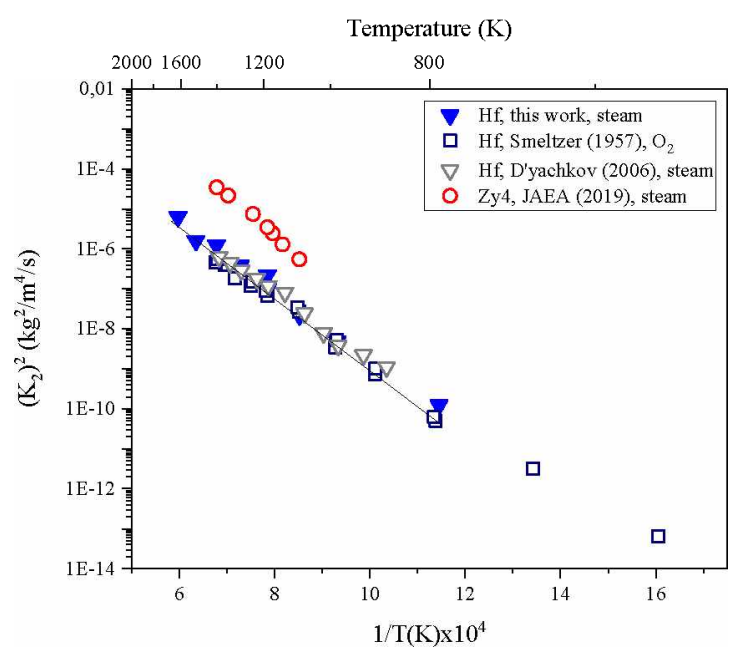

Figure 17: Parabolic rate constants in the 600 to $1400^{\circ} \mathrm{C}$ temperature range for hafnium rods/discs

Using the Arrhenius relation for the temperature variation of the oxidation rate constant, a linear regression of the data gives:

$$
K_{2}^{2}=A \exp \left[\frac{-E_{a}}{R T}\right]
$$

with:

- $E_{a}$, the activation energy $\left(\mathrm{J} \mathrm{mol}^{-1}\right), E_{a}=189.2 \mathrm{~kJ} \mathrm{~mol}^{-1}$,

- $T$, the absolute temperature (K),

- $A=5.185 \mathrm{~kg}^{2} \mathrm{~m}^{-4} \mathrm{~s}^{-1}$,

- $R$, the ideal gas constant, $R=8.31 \mathrm{~J} \mathrm{~mol}^{-1} \mathrm{~K}^{-1}$.

The value of the activation energy $E_{a}$ is slightly higher than the one obtained by D'yachkov, $125 \mathrm{~kJ} \mathrm{~mol}^{-1}$ in the 1100 to $1200^{\circ} \mathrm{C}$ temperature range [12], even if these values are not directly comparable taken into account the fact that D'yachkov put in evidence the parabolic regime only in a limited period of time. The value reported by Smeltzer [25], $150.5 \mathrm{~kJ} \mathrm{~mol}^{-1}$ from oxidation tests under oxygen are in good agreement with our results.

Oxygen concentration profiles in the metal below the oxide layer were determined by EPMA for the longest oxidation durations on two opposite radial locations for each rod sample. The profiles show that oxygen diffuses in the metal down to a few hundreds um (Figure 18). Assuming that the metal is in equilibrium with the oxide and that the diffusion coefficient is independent of the concentration, the oxygen concentration $C(x, t)$ at time $t$ and distance $x$ from the metal/oxide interface is given by the expression: 


$$
\frac{C(x, t)}{C_{0}}=\operatorname{erfc}\left(\frac{x}{\sqrt{D(T) t}}\right)
$$

with:

- $D(T)$, the diffusion coefficient $\left(\mathrm{m}^{2} \mathrm{~s}^{-1}\right)$,

- $x$, the distance from the sample surface $(\mathrm{m})$,

- $t$, the time (s),

- $C_{0}$, the oxygen concentration at the sample surface (normalized to 1).

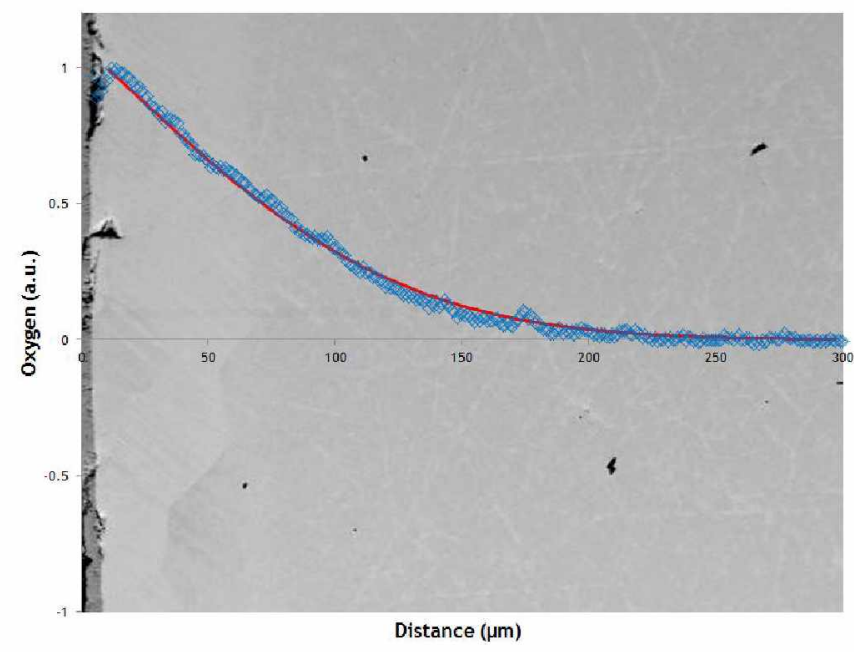

Figure 18: Experimental oxygen profile in hafnium (red line) and EPMA measured profile (blue points) after steam oxidation for two hours at $1200^{\circ} \mathrm{C}$

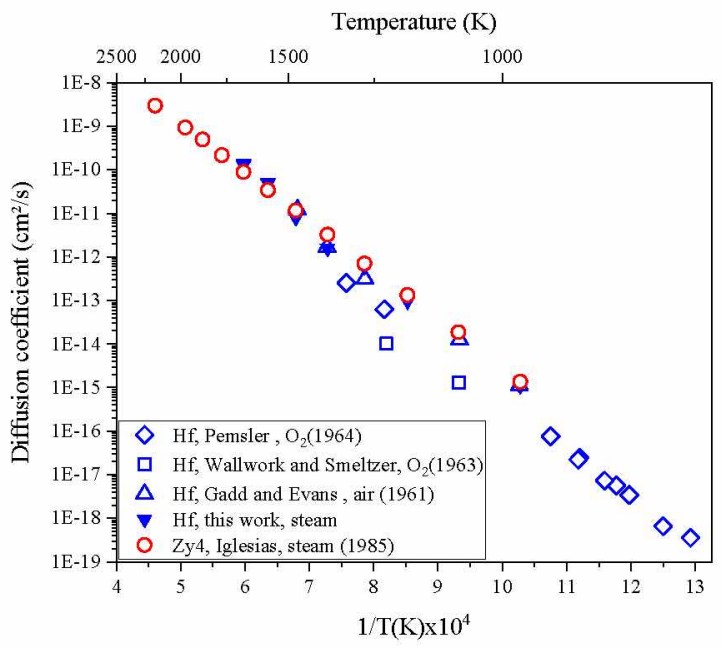

Figure 19: Temperature dependence of the diffusion coefficient of oxygen in hafnium in this work and as reported in previous studies, compared to the diffusion coefficient of oxygen in Zircaloy-4 [26]
The oxygen diffusion coefficient is estimated at each temperature by fitting Equation (3) to the experimental profiles. The temperature variation of the diffusion coefficient is assumed to follow the Arrhenius-type relation:

$$
D(T)=D_{0} \exp \frac{-E_{a}}{R T}
$$

with:

- $E_{a}$, the energy of activation $\left(\mathrm{J} \mathrm{mol}^{-1}\right)$,

- $T$, the absolute temperature (K),

- $D_{0}$, a pre-exponential factor $\left(\mathrm{m}^{2} \mathrm{~s}^{-1}\right)$,

- $R$, the ideal gas constant, $R=8.31 \mathrm{~J} \mathrm{~mol}^{-1} \mathrm{~K}^{-1}$.

A linear regression of the data gives $E_{a}=224 \mathrm{~kJ} \mathrm{~mol}^{-1}$ and $D_{0}=1.05 \times 10^{-3} \mathrm{~m}^{2} \mathrm{~s}^{-1}$.

Many determinations of oxygen diffusion in $\alpha$-hafnium are available in literature (Table 3). Our data can be straightforwardly compared to effective diffusion coefficient obtained in comparable oxidation experiments [27-30] (Figure 19). Among these experiments, Pemsler [27, 28] determined the diffusion coefficient of oxygen in hafnium by anodic dissolution of hafnium oxide film. Prior to dissolution, samples were exposed to oxygen at $900^{\circ} \mathrm{C}$ and $1 \mathrm{~atm}$ for different durations. Later the oxygen diffusion coefficient in $\alpha$-Hf was determined again by the same author [28] using a similar technique for a different range of temperatures. The Pemsler's values were confirmed in a separate study, by Kofstad [30], who reported values obtained from high temperature oxidation experiments of hafnium by TGA. Our data are consistent with these values. In particular the value for the energy of activation, $E_{a}$, $224 \mathrm{~kJ} \mathrm{~mol}^{-1}$, is in good agreement with the one obtained by Pemlser [27, 28], $217 \mathrm{~kJ} \mathrm{~mol}^{-1}$. By contrast the values determined by Wallwork and Smeltzer [29] are significantly smaller than ours. These authors reported values for the diffusion coefficient at $800^{\circ} \mathrm{C}$ and $950{ }^{\circ} \mathrm{C}$ obtained by microhardness measurements performed on oxidized samples. Bernardi et al. [31] argued that micro-hardness technique is not reliable to get accurate diffusion coefficients. In addition, Wallwork and Smeltzer [29] reported data at only two temperatures, leading then to a very large uncertainty for the activation energy.

By means of DF'T calculations, Wu et al. $[32,33]$ and O'Hara et al. $[34,35]$ reported an activation energy matching very well with our data. Nevertheless, one has to keep in mind that the values of activation energy and diffusion coefficient calculated by DFT are not expected to be in agreement with the values obtained from our tests. Indeed in DFT, the diffusion coefficient is determined from the examination of atomic jump process in a defect-free material whereas, in our tests, a so-called effective diffusion coefficient is only accessible, considering the different contributions to the oxygen transport process (bulk diffusion with presence of point and extended defects, impurities and grain boundary diffusion). Our activation energy also matches very well with the experimental data reported by Vykhorets et 
al.[36] who used the combination of oxygen implantation and nuclear resonance methods in a range of temperatures rather low in comparison with ours. A very different result obtained by the same technique is reported by Bernardi et a1. [31]. The Hf vacancies created during the irradiation phase of the experiments and not thermalized could act as trapping sites for oxygen and then should contribute to decrease the oxygen diffusion coefficient. For that reason, the lower value of the activation of Bernadi et al. is rather unexpected. The preliminary DFT investigation by O'Hara et al. $[34,35]$ seems to indicate that the trapping of oxygen in vacancies is not favorable from an energetics point of view and then vacancies should not affect the oxygen diffusion process. The agreement with the activation energy determined from air oxidation experiments [37] is more surprising since it should be expected that the oxygen gradient in the metal is impacted by the presence of nitrogen one. Nevertheless abinitio calculations as well as experimental data $[34,35]$ showed that nitrogen diffuses more slowly than oxygen in $\alpha$-Hf such as the oxygen gradient may not be strongly modified by the presence of nitrogen. This agreement is indirectly an indication that the same specie, diffuses across the oxide layer in both air and steam atmosphere, presumably molecular or atomic oxygen.

Comparison of the diffusion coefficient of oxygen in hafnium and in Zircaloy-4 shows that they are of the same order of magnitude. By means of DFT calculations, Wu et al. [32, 33] effectively reported that oxygen interstitial site energies and diffusion barriers in both metal hcp structures are very similar as well as the diffusion process.

\subsubsection{Mixed regime characterization}

The Evans' equation [13] is a convenient way to take into account the parabolic and linear mixed characters of an oxidation kinetics. D'yachkov [12] stipulated that his data could be described within the framework of this mixed regime. In this model for which Deal et al. [39] derived all the equations briefly recalled therafter, the oxidation process is divided into three successive steps describing the oxidant species transport from the gas phase towards the metallic surface:

- in the first step, the oxidant is transported from the bulk of the oxidizing gas to the outer surface where it reacts or is adsorbed. The flux of the oxidant from the gas to the vicinity of the outer surface of the sample is taken to be:

$$
F_{\text {gas }}=h_{\text {gas }}\left(C_{\text {gas }}-C_{\text {out }}\right)
$$

where $h_{\text {gas }}$ is a gas-phase transport coefficient, $C_{\text {out }}$ is the concentration of the oxidant at the outer surface of the oxide layer, and $C_{g a s}$ is the equilibrium concentration of the oxidant.

- the second step involves the transport of the oxidant across the oxide layer towards hafnium metal. The flux of oxygen across the oxide layer is given by Fick's law:

$$
F_{\text {dif }}=\frac{D_{e f f}}{y}\left(C_{\text {out }}-C_{\text {inn }}\right)
$$

where $D_{e f f}$ is the effective diffusion coefficient of oxygen across the oxide layer, $y$, the oxide layer thickness, and $C_{i n n}$ is the concentration of oxygen at the inner surface of the oxide layer.

- the final step is the reaction of oxygen with metallic hafnium. The flux corresponding to the oxidation reaction assuming to be a first-order one can be expressed as follows:

$$
F_{o x i}=h_{o x i} C_{i n n}
$$

By assuming a steady-state hypothesis, i.e. $F_{\text {gas }}=F_{d i f}$ and $F_{\text {dif }}=F_{\text {oxi }}$, one obtains [39]:

$$
F=F_{g a s, d i f f, o x i}=\frac{h_{o x i} C_{g a s}}{1+\frac{h_{o x i}}{h_{g a s}}+\frac{h_{o x i}}{D_{e f f}} y}
$$

The rate of formation of the oxide layer is then given by:

$$
\frac{d y}{d t}=\frac{F}{N_{O_{2}}}=\frac{1}{N_{O_{2}}} \frac{h_{o x i} C_{g a s}}{1+\frac{h_{o x i}}{h_{\text {gas }}}+\frac{h_{o x i}}{D_{\text {eff }}} y}
$$

where $\mathrm{N}_{\mathrm{O}_{2}}$ is the number of oxidant molecules incorporated into a unit volume of the oxide layer. After integration, the evolution of $y$ versus time is given by:

$$
y^{2}+\frac{K_{2}}{K_{1}} y=K_{2} t
$$

where $K_{1}$, and $K_{2}$ are defined by the following expressions:

$$
\begin{gathered}
K_{2}=\frac{2 D_{e f f} C_{g a s}}{N_{O_{2}}} \\
K_{1}=\frac{C_{g a s}}{N_{O_{2}}} \frac{h_{o x i} h_{g a s}}{h_{o x i}+h_{\text {gas }}}
\end{gathered}
$$

The solution of Equation (10) is given by:

$$
y=\frac{K_{2}}{K_{1}}\left[1+\frac{4 K_{1}^{2} t}{K_{2}}\right]^{1 / 2}-\frac{K_{2}}{2 K_{1}}
$$

For large times, the previous equation is reduced to a pure parabolic kinetics:

$$
y^{2}=K_{2} t
$$

whereas for small times, it is reduced to a pure linear kinetics:

$$
y=K_{1} t
$$

Coming back to Equation (10), it can be used to process our data at shorter times (before $1000 \mathrm{~s}$ ) as follows:

$$
y=K_{2} \frac{t}{y}-\frac{K_{2}}{K_{1}}
$$

The previous equation which gives the evolution of the oxide layer as function of time cannot be straigthforwardly applied to the mass evolution since mass gain not only reflects oxide layer 
Table 3: Difffusion coefficient of oxygen in $\alpha$-hafnium reported in previous studies

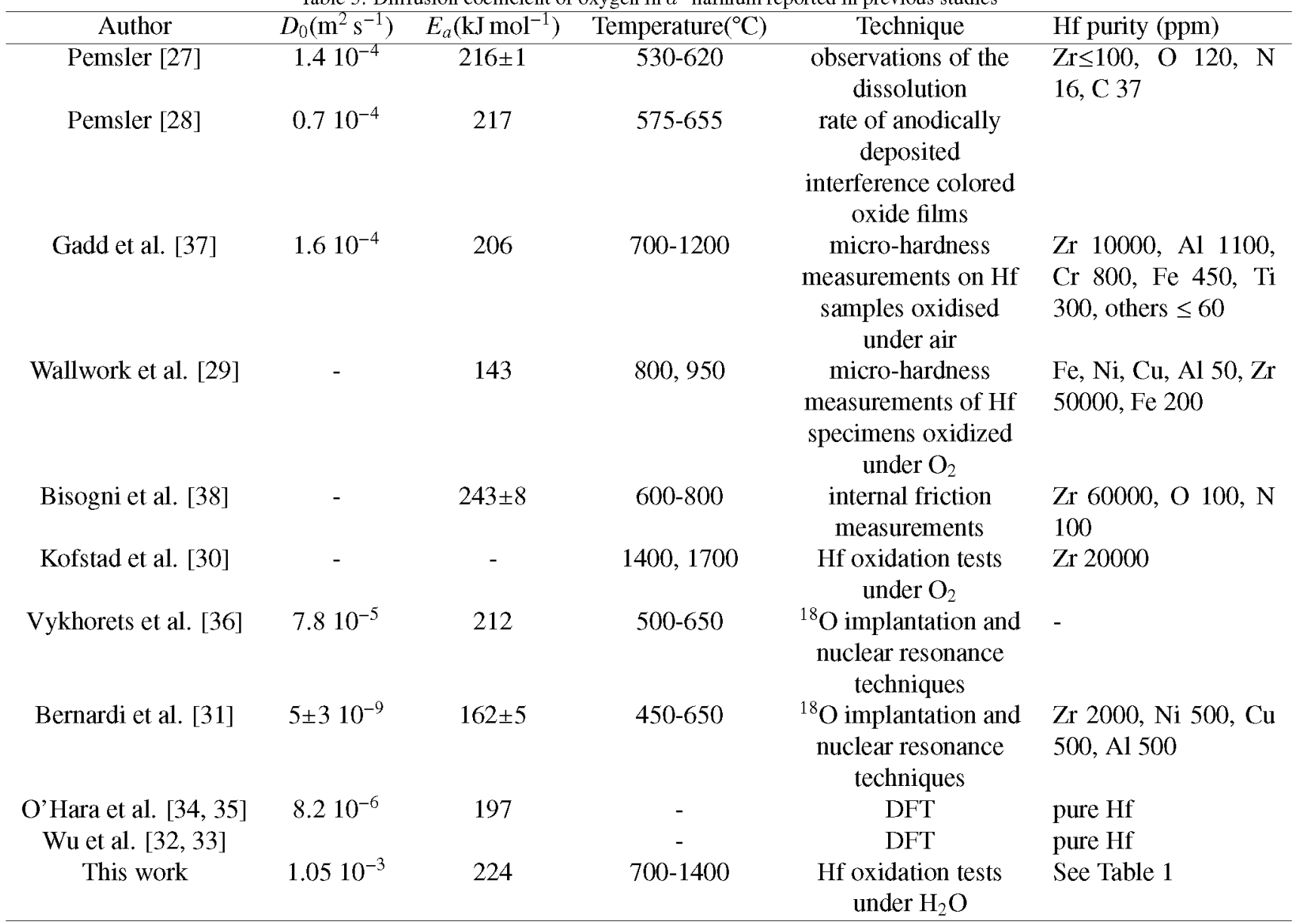

growth but also oxygen dissolution in the metal ${ }^{2}$. Assuming oxygen diffusion in the metal to be rate-determining in the oxygen dissolution process and that the oxygen concentration at the surface is not limited by the supply of gaseous oxygen, the total amount of solute, $M(t)$, diffusing into a semi-infinite $\mathrm{Hf}$ solid from a surface with constant surface composition during the time period from 0 to $t$ is given by:

$$
M(t)=\frac{2}{\sqrt{\pi}} c_{S} \sqrt{D t}
$$

where $D$ stands for the oxygen diffusion in $\alpha-\mathrm{Hf}$ and $c_{s}$, the oxygen saturation concentration in the metal. Taking $c_{s}$ to be 20 at.\% [40] and employing our value for the diffusion coefficient, the value of $M(t)$ as a function of time at $1200^{\circ} \mathrm{C}$ is compared to the measured kinetics until $1000 \mathrm{~s}$ (Figure 20). It can be seen that the measured mass gain is lower than the mass increase due to oxygen dissolution in the metal over this period. It means that the oxygen dissolution is not the limiting

\footnotetext{
${ }^{2}$ Strictly speaking, the hydrogen uptake by the material should be considered in the mass uptake, so that it can be subtracted in order to apply the model that describes only the oxygen mass uptake. Nevertheless the quantities of hydrogen absorbed by the material remain low even at the end of the test so that this correction can be neglected at the short times as well as at long times.
}

process in the Hf oxidation and then Equation (16) can be used. According to Equation (16) then applicable to the mass gain, the experimental data plotted in an $t /(\Delta m / S)$ axis system (socalled Evans' coordinates), should be represented by a linear expression (Figure 21). Straight lines are obtained for the different temperatures with the values of $K_{2}$ (slopes of the lines), increasing with temperature. These lines theoretically intercept the y-axis for $y=-K_{2} / K_{1}$. For the lowest temperatures $\left(800^{\circ} \mathrm{C}\right.$ to $1000^{\circ} \mathrm{C}$ ), the lines cross the $y$-axis near 0 , that means that $K_{1}$ tends to $\infty$ (for non-zero $K_{2}$ ). For these temperatures, the kinetics is then predominantly parabolic. D'yachkov calculated for $K_{2} / K_{1}$ from his data at 800 and $900^{\circ} \mathrm{C}, 0.15$ and 0.29 respectively. For higher temperatures, the accurracy of our data at very short times do not allow to determine $K_{2} / K_{1}$ with precision, but it can be stated that in our experiments, the ratio $K_{2} / K_{1}$ is very low. It indicates that the parabolic contribution in the initial corrosion regime is dominant.

\subsection{Claddings}

In Figure 22, we have performed a linear regression of our data related to claddings for times higher than $1000 s$ in a $\mathrm{Ln}$ (weight gain)-Ln(time) plot. It is then possible to establish that, after the initial oxidation regime lasting about $1000 \mathrm{~s}$, the 


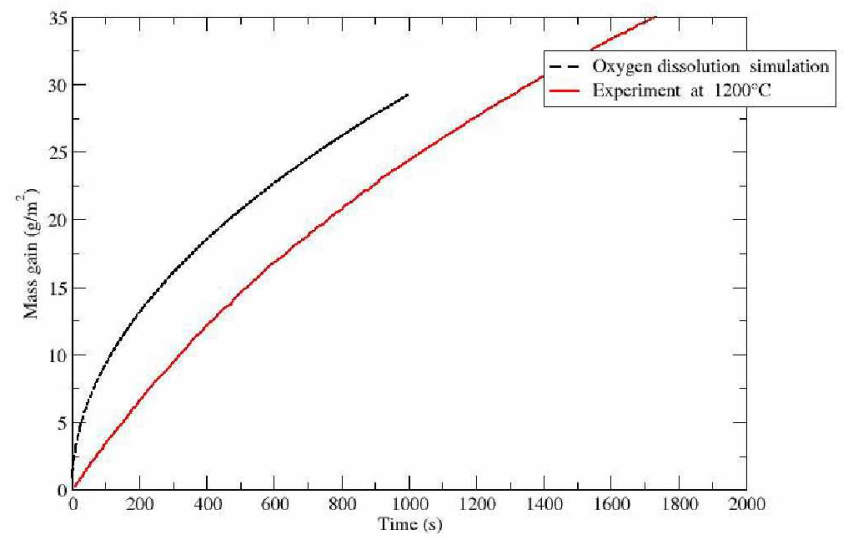

Figure 20: Measured mass gain at $1200^{\circ} \mathrm{C}$ compared to simulated mass gain due to oxygen dissolution in the metal

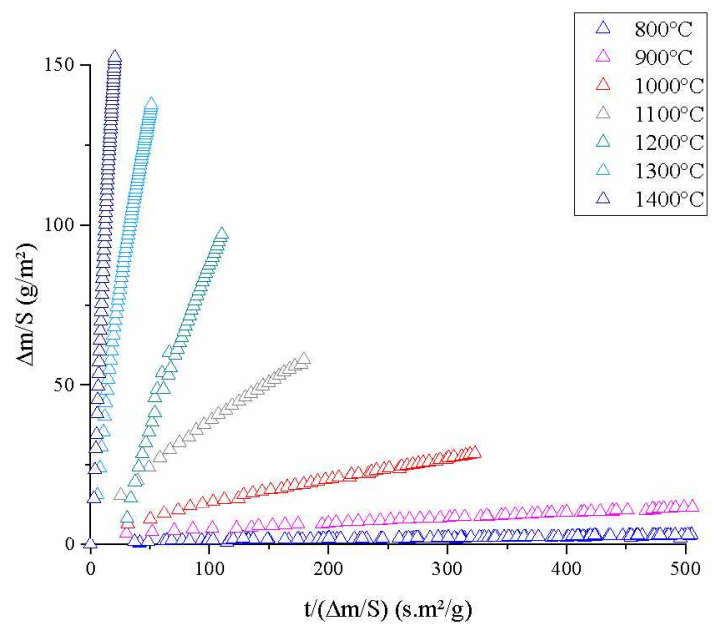

Figure 21: Weight gain in the 800 to $1400^{\circ} \mathrm{C}$ temperature range as function of times represented in the Evans' coordinates system for hafnium rods and discs for times lower than $1000 \mathrm{~s}$

oxidation kinetics of hafnium in steam in the temperature range between 800 and $1200^{\circ} \mathrm{C}$ follows a power law with $n$ between 3.2 and 4.2 (Figure 23). Given the spread of the $n$ constant, it was not possible to evaluate the activation energy in the tested temperature conditions.

\section{Summary and conclusion}

To assess the impact of using hafnium in reactor plants in case of severe nuclear accidents, the oxidation behavior of hafnium was studied up to $1400^{\circ} \mathrm{C}$. Samples were oxidised in steam/argon mixtures, either in furnaces or in thermogravimetric analyzers. For hafnium rods or discs, metallographic examinations show the presence of a dense and protective oxide film

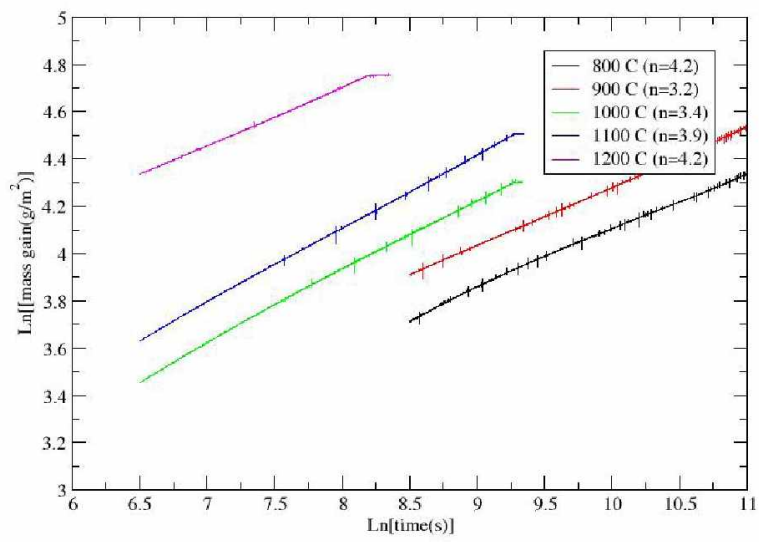

Figure 22: Weight gain in the 800 to $1200^{\circ} \mathrm{C}$ temperature range as function of times for hafnium claddings for times higher than about $1000 \mathrm{~s}$

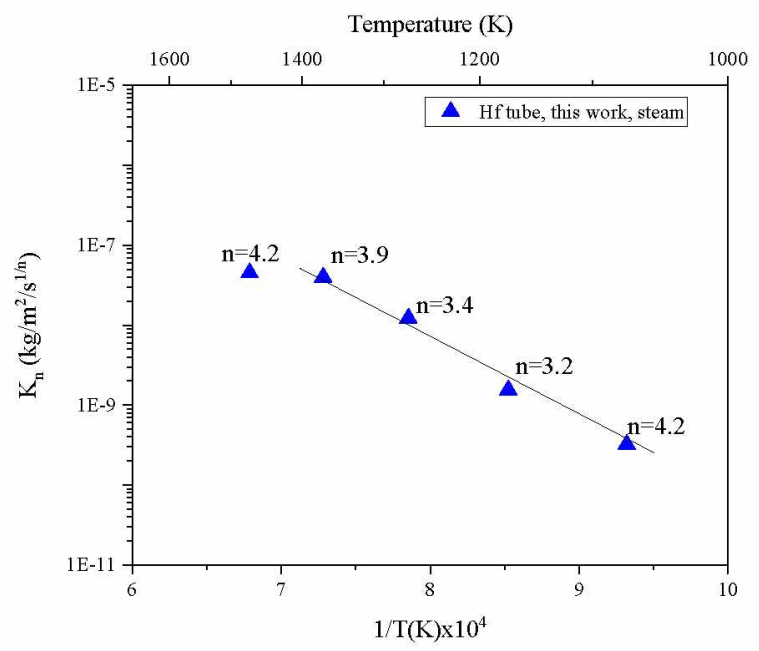

Figure 23: Oxidation rate constants in the temperature range 800 to $1200^{\circ} \mathrm{C}$ for hafnium cladding

after steam oxidation. The oxidation rate may be described by a parabolic law in the tested temperature range after an initial oxidation regime of $\approx 1000 \mathrm{~s}$, and the value of the activation energy for the parabolic rate constant is in good agreement with the ones published in the literature. The estimated oxygen diffusion coefficient in the $\alpha$-Hf phase from our measurements is in good agreement with published data.

Hafnium claddings led to weight gains much higher than the ones measured on hafnium rods or discs. Above $800^{\circ} \mathrm{C}$, after some times, the reaction rate for hafnium cladding follows a cubic to quartic law. Metallographic examinations show the presence of non protective oxide layer after steam oxidation. These tests highlighted the influence of the surface conditions on the oxidation rate of hafnium in steam and probably the influence of iron content. However, the oxidation rate of 
hafnium remains in any tested conditions well below the oxidation rate of zirconium alloys in the same temperature range. Additionally, the bundle test terminated by reflood showed that the residual strength of oxidized Hf claddings was sufficient to prevent the cladding fragmentation during quenching.

\section{Acknowledgements}

The authors would like to acknowledge O. Coindreau and C. Duriez from IRSN for the fruitful discussions regarding the interpretation of the data presented in this paper. 


\section{References}

[1] H. Keller, J. Shallenberger, D. Hollein, C. Hott, Development of Hafnium and Comparison with Other Pressurized Water Reactor Control Rod Materials, Nuclear Technology 59 (1982) 476-482.

[2] V. D. Risovaniy, A. V. Zaharov, E. P. Klochkov, E. E. Varlashova, D. N. Suslov, A. B. Ponomarenko, A. V. Scheglov, Dysprosium and Hafnium Base Absorbers for Advanced WWER Control Rods, in: Technical Committee Meeting, Control Assembly Materials for Water Reactors: Experience, Performance and Perspectives, Vienna, 1998, pp. 91-102.

[3] H. Shirayanagi, T. Fukumoto, S. Shiga, Advanced Control Rods for Japanese BWR Plants, in: Proceedings, IAEA Technical Committee meeting on Advances in Control Rod Assembly Materials for Water Reactors, 1993, p. 135

[4] J. Stuckert, M. Grosse, Y. Onel, C. Rossger, U. Stegmaier, M. Steinbrück, Results of the QUENCH-DEBRIS (QUENCH-17) test with strongly oxidized Zircaloy-4 and Hafnium claddings filled with segmented pellet simulators, Technical Report QUENCH-DEBRIS: NUSAFE-3572, KIT, 2018.

[5] G. Salvaggio, F. Nichols, J, Bacca, Properties of a Hafnium Control Rod After Exposure During Two Seed Lives in PWR Core 1, Technical Report WAPD-TM-337, U.S. Atomic Energy Commission, 1962.

[6] G. Salvaggio, J. Weinberg, S. Kass, K. Longua, Properties of a Hafnium Control Rod After Exposure During Three Seed Lives in PWR Core 1, Technical Report WAPD-TM-547, U.S. Atomic Energy Commission, 1965.

[7] D. Rishel, J. Smee, B. Kammenzind, The Corrosion Behaviour of Hafnium in High-Temperature-Water Environments, Technical Report BT-3232, Bettis Atomic Power Laboratory, 2000.

[8] D. Rishel, J. Smee, B. Kammenzind, The Corrosion Behavior of Hafnium in High-Temperature Water Environments, Journal of Nuclear Materials 303 (2002) 210-225.

[9] V. Chernishov, I. Vasilchenko, Control Members of WWER-440 and WWER-1000 Power Reactors, in: Proceedings, IAEA Technical Committee meeting on Advances in Control Rod Assembly Materials for Water Reactors, 1993, p. 105.

[10] R. Kuwae, T. Hatanaka, J. Kawashima, S. Shima, Hafnium Corrosion Behavior in High-Temperature Steam, Journal of Nuclear Materials 139 (1986) 42-47.

[11] R. Grebennikov, F. Shamashov, Mechanical Properties and Corrosion Resistance of Hafnium-Zirconium Alloys in a Steam-Water Medium, Soviet Atomic Energy 14 (1964) 285-290.

[12] V. D'yachkov, High-Temperature Oxidation of Titanium, Zirconium, and Hafniyum in Steam, Russian Journal of Applied Chemistry 79 (2006) 896-902.

[13] U. Evans, The Relation Between Tranishing and Corrosion, Transactions of the American Electrochemical Society 46 (1925) 247-282.

[14] D. Shin, R. Arroyave, Z.-K. Liu, Thermodynamic Modeling of the Hf-SiO System, Calphad 30 (2006) 375-386.

[15] A. Hermann, W. Holger, R. Bühner, M. Steinemann, G. Bart, Hydrogen distribution between fuel cladding metal and overlying corrosion layers, in: Proceedings, International Topical Meeting on LWR Fuels, 2000, pp. 372-384.

[16] M. Grosse, E. Lehmann, M. Steinbrück, G. Kühne, J. Stuckert, Influence of oxide layer morphology on hydrogen concentration in tin and niobium containing zirconium alloys after high temperature steam oxidation, Journal of Nuclear Materials 385 (2009) 339-345.

[17] P. Elliott, Hydrogen-Hafnium, Constitution of Binary Alloys, First Supplement, McGraw-Hill Book Company, 1985, p. 496.

[18] J. Stuckert, M. Grosse, Y. Onel, C. Rössger, M. Steinbrück, Results of the QUENCH-DEBRIS test, in: Proceedings of International Congress on Advances in Nuclear Power Plants ICAPP2014, paper 14150, volume 2, pages $1123-1128,2014$

[19] J. Cathcart, R. Pawel, R, McKee, R. Druschel, G. Yurek, J. Campbell, S. Jury, Zirconium metal-water oxidation kinetics IV. Reaction rate studies, Technical Report ORNL/NUREG-17, ORNL, 1977.

[20] R. Pawel, J. Cathcart. J. Campbell, The Oxidation of Zircaloy-4 at 900 and $1100 \mathrm{C}$ in High Pressure Steam, Journal of Nuclear Materials 82 (1979) 129-139.

[21] S. Leistikow, G. Schanz, The Oxidation of Zircaloy-4 in Steam Between 600 and 1600 C, Werstoffe und Korrosion 36 (1985) 105-116
[22] H. Uetsuka, P. Hofmann, High-Temperature Oxidation Kinetics of Zircaloy-4 in Oxygen/Argon Mixtures, Journal of Nuclear Materials 168 (1989) 47-57.

[23] G. Schanz, Semi-Mechanistic Approach for the Kinetic Evaluation of Experiments on the Oxidation of Zirconium Alloys, Technical Report FZKA 7329, FZK, 2007

[24] G. Sabol, S. Dalgaard, The Origin of the Cubic Rate Law in Zirconium Alloy Oxidation. Journal of the Electrochemical Society 122 (1960) 316 317.

[25] W. Smeltzer, M. Simnad, Oxidation of Hafnium, Acta Metallurgica 5 (1957) 328-394.

[26] F. Iglesias, D. Duncan, S, Sagat, H. Sills, Verification of the From Model for Zircaloy Oxidation During High Temperature Transients, Journal of Nuclear Materials 130 (1985) 36-44.

[27] J. Pemsler, Diffusion of Oxygen in Hafnium, Journal of the Electrochemical Society 106 (1959) 1067-1068.

[28] J. Pemsler, Diffusion of Oxygen in Hafnium, Journal of the Electrochemical Society 111 (1964) $1185-1186$.

[29] G. Wallwork, W. Smeltzer, The Diffusion of Oxygen in Hafnium, The Journal of The Electrochemical Society 11 (1963) 943-944.

[30] P. Kofstad, S. Espevik, Kinetic Study of High-Temperature Oxidation of Hafnium, Journal of the Less Common Metals 12 (1967) 382-394.

[31] F. Bernardi, M. Behar, A. Ruzzarin, J. Dos Santos, F. Dyment, Diffusion Study of ${ }^{18} \mathrm{O}$ Implanted Into $\alpha$-Hf Using the Nuclear Resonance Technique, Applied Physics A 83 (2006) 37-40.

[32] H. Wu, P. Wisesa, D. Trinkle, Oxygen Diffusion in hep Metals From First Principles, Physical Review B 94 (2016) 014307.

[33] H. Wu, Oxygen Diffusion Through Titanium and Other HCP Metals, $\mathrm{Ph} . \mathrm{D}$. thesis, University of Illinois, 2013.

[34] A. O'Hara, A. Demkov, Oxygen and Nitrogen diffusion in $\alpha$-Hafnium from First Principles, Applied Physics Letters 104 (2014) 211909.

[35] A. O'Hara, Metal-to-Insulator Transitions in Transition Metal Oxides: A First Principles Study, Ph.D, thesis, University of Texas, 2015.

[36] V. Vykhorets, T. Kurennykh, Physics of Metals and Metallography 76 (1993) 115

[37] J. Gadd, E. Evans, High Temperature Scaling of Hafnium in Air, Corrosion 17 (1961) 441t-445t.

[38] E. Bisoni, G. Mah, C. Wert, Diffusion of Gases in Special Interstitial Sites in Hafnium, Journal of the Less Common Metals 7 (1964) 197-204.

[39] B. Deal, A. Grove, General Relationship for the Thermal Oxidation of Silicon, Journal of Applied Physics 36 (1965) 3770.

[40] H. Okamoto, Hf-O (Hafnium-Oxygen), Journal of Phase Equilibria and Diffusion 29 (2008) 124. 